\title{
Profitability Analysis (A comparative study of SAIL \& TATA Steel)
}

\author{
Dr. Monica Tulsian
}

\begin{abstract}
The main purpose of a business unit is to make profit. The profitability analysis is done to throw light on the current operating performance and efficiency of business firms. It should be duly noted that net income figure alone is not very helpful in determining the efficiency and performance of the business firm unless it is related to some other figures such as sales, cost of goods sold, operating expenses, capital invested etc.

Thus the profitability ratios are calculated to enlighten the end result and comparison of business firms which is the sole criterion of overall efficiency of business concern.
\end{abstract}

\section{Meaning \& Concept of profitability:-}

The word profitability is composed of two words, namely, profit and ability. The term profit has been explained above and the term ability indicates the power of a business entity to earn profits. The ability of a concern also denotes its earning power or operating performance. The profitability may be defined as the ability of a given investment to earn a return from its use.

Profitability is a relative concept whereas profit is an absolute connotation. Despite being closely related to and mutually interdependent, profit and profitability are two different concepts. In other words, in spite of their generic nature, each one of them has a distinct role in business.

As an absolute term, profit has no relevance to compare the efficiency of a business organization. A very high profit does not always indicate sound organizational efficiency and low profitability is not always a sign of organizational sickness. Therefore, it can be said that profit is not the prime variable on the basis of which the operational efficiency and financial efficiency of an organization can be compared. To measure the productivity of capital employed and to measure operational efficiency, profitability analysis is considered as one of the best techniques. .

\section{Methodology:-}

The primary purpose of present study has been to obtain a deep insight and full familiarity with the profitability of the companies of steel industry in India. The present study is based on the secondary data i.e. annual reports and accounts of the companies selected for the study. A five yearly period commencing from 2007-08 to 2011-12 has been taken. Steel Authority of India Ltd. (Public Sector unit) and Tata Steel ( Private Sector) has been selected for the purpose of the study. Profitability of the companies selected for study has been analyzed with the help of ratio analysis and various ratios have been calculated. Statistical tools such as average, standard deviation and coefficient of variation has been used to interpret the data. Hypothesis has been tested by using t test.

Hypothesis: The present study is based on the following null hypothesis-

"There is no significant difference in the profitability of the companies under study

\section{Analysis of Profitability:}

Profitability of the companies under study has been analyzed by calculating the following ratios:

a)

Gross Profit Ratio:

The gross profit ratio is also known as gross profit margin and this ratio expresses the relationship of gross profit to net sales (cash and credit) in terms of percentage. This ratio is calculated to find the profitability of business. A high gross profit ratio is a symbol of good management. The main objective of computing this ratio is to determine the efficiency with which production and/or purchase operations and selling operations are carried on. In the present study the gross profit ratio has been calculated by using the following formula:

Gross profit

$$
\text { Gross profit ratio }=\quad \text { Net sales }
$$

The gross profit ratio of the companies under study has been shown in the following table 
Table 1

Gross Profit Ratio of the Companies under Study From 2007-08 to 2011-12

(Ratio in Percentage)

\begin{tabular}{|c|c|c|}
\hline Years & SAIL & Tata Steel \\
\hline $2007-08$ & 50.05 & 40.87 \\
\hline $2008-09$ & 42.51 & 36.15 \\
\hline $2009-10$ & 38.26 & 34.47 \\
\hline $2010-11$ & 20.78 & 29.14 \\
\hline $2011-12$ & 15.19 & 34.80 \\
\hline Average & 33.36 & 3.82 \\
\hline SD & 13.22 & 10.98 \\
\hline
\end{tabular}

Source: Annual Reports and Accounts of the Companies under study

\section{Inference:}

It can be noted from the above table that the gross profit ratio of SAIL showed a decreasing trend during the whole period of study because during the year 2007-08 the gross profit ratio was 50.05 percent which constantly kept on decreasing and came down to 15.19 percent in 2011-12. The average of the gross profit ratio was 33.36 percent which can be regarded favorable but decreasing trend of the ratio denotes an inefficient management. The decreasing trend of the ratio was mainly because of increase in the cost of goods sold. It can be suggested that the management of the company should try to control the cost of goods sold and increase the sales.

The above table also shows that the gross profit ratio of Tata Steel showed a decreasing trend during the whole period of study and varied within the range of 40.87 percent in 2007-08 to 29.14 percent in 2011-12. The average of the ratio was 34.80 percent which shows a favorable position of the gross profit ratio but decreasing trend shows inefficiency of the management and it is suggested that the management of the company should try to control the decreasing trend of the ratio by controlling the cost of goods sold and by increasing the sales.

On the basis of the average of the gross profit ratio it can be concluded that Tata Steel performed better though the gross profit ratio showed a decreasing trend, however, the decrease in the gross profit ratio was less than the decrease in the gross profit ratio of SAIL. The fluctuations in the gross profit ratio were high as the coefficient of variation was 39.63 percent which should be controlled while the coefficient of variation of gross profit ratio for Tata Steel was 10.98 percent showing a moderate consistency in the ratio.

Test of Hypothesis: - Following hypothesis has been tested by using t test

Null Hypothesis (Ho):- There is no significant difference in the gross profit ratio of the companies under study.

Computed value of $\mathrm{t}=0.23$

Degree of Freedom $(\mathrm{v})=\mathrm{N} 1+\mathrm{N} 2-2=8$

Critical value of $t$ at 5 percent level of significance (for $v=8$ ) is 2.31

\section{Decision: -}

Since the computed value of $t$ is less than the critical value of $t$ at 5 percent level of significance, hence the null hypothesis is accepted and it can be concluded that the difference in the gross profit ratio of the companies under study is not significant and both the companies are same as regards the gross profit ratio.

b)

\section{Operating Profit Ratio}

This ratio establishes the relation between operating profit and net sales. The main objective of computing this ratio is to determine the operational efficiency of the management. This ratio is also called operating profit margin. Operating profit means the net profit arising from the normal operations and activities of the business without taking into account of extraneous transactions and expenses of purely financial nature. Higher the operating ratio, the better would be the operational efficiency of the business. A higher operating profit ratio means that the business has been able not only to increase its sales but also been able to cut down its operating expenses. Operating profit ratio can be calculated by formula as follows: Operating Profit Ratio $=\frac{\text { Operating Profit }}{\text { Net Sales }} \quad$ X100 
Table 2

Operating Profit Ratio of the Companies under Study

From 2007-08 to 2011-12

(Ratio in Percentage)

\begin{tabular}{|c|c|c|}
\hline Years & SAIL & TISCO \\
\hline $2007-08$ & 19.06 & 36.63 \\
\hline $2008-09$ & 10.72 & 32.15 \\
\hline $2009-10$ & 12.80 & 30.14 \\
\hline $2010-11$ & 16.37 & 38.11 \\
\hline $2011-12$ & 13.15 & 35.50 \\
\hline Average & 14.42 & 34.51 \\
\hline S.D. & 2.94 & 2.94 \\
\hline C.V. $(\%)$ & 20.39 & 8.52 \\
\hline
\end{tabular}

Source: Annual Reports and Accounts of the Companies under study.

\section{Inference:}

It can be noted from the above table that the operating profit ratio of SAIL showed a mixed fluctuating trend during the period of study and varied within the range of 19.06 percent in 2007-08 to 10.72 percent in 2008-09. The average of the ratio was 14.42 percent which can be regarded satisfactory but the decreasing trend of the ratio should be controlled by the management of the company.. For this purpose efforts should be made to control and reduce the operating cost and increase the sales.

For TISCO, the operating profit ratio also showed a mixed fluctuating trend during the period of study. Initially, during 2007-08, the operating profit ratio was 36.63 percent which decreased to 32.15 percent in 200809 and further to 30.14 percent in 2009-10. The operating profit ratio increased to 38.11 percent in $2010-11$ but further decreased to 35.50 percent in 2011-12. The average of the ratio was 34.51 percent which can be regarded good and denotes an efficient management. However, decreasing trend should be controlled.

An overall study of operating profit ratio shows that TISCO has performed better than SAIL from the view point of operating profit ratio because the average operating ratio for TISCO was 34.51 percent while for SAIL it was 14.42 percent. Coefficient of variation for SAIL was higher than that of TISCO denoting variability in the ratio.

Test of Significance (T-Test)

Null Hypothesis (Ho) : There is no significant difference in the operating ratio of the companies under study.

Calculated value of $\mathrm{t}=10.80$ :

Degree of Freedom $(v)=5+5-2=8$

Critical value of $t$ at 5 percent level of significance is 2.31

Decision: Since the computed value of $t$ is more than the critical value of $t$, hence the null hypothesis is rejected and it is concluded that there is a significant difference in the operating profit ratio of the companies under study.

C) Return on capital Employed Ratio:

This ratio establishes the relationship between profit and capital employed and is calculated in percentage by dividing the net profit by capital employed. follows:

It is also a measure of earning power of the net assets of the business. It is calculated by formula as

Return on capital employed Ratio :

Net profit (PBIT) x 100

Capital Employed

The return on capital employed ratio of the companies under study has been shown in the following table:

Table 3

Return Capital Employed Ratio of Companies under study (From 2007-08 to 2011-12) (Ratio in Percentage)

\begin{tabular}{|c|c|c|}
\hline Years & SAIL & TISCO \\
\hline $2007-08$ & 44.99 & 16.46 \\
\hline $2008-09$ & 27.17 & 14.44 \\
\hline $2009-10$ & 21.09 & 13.58 \\
\hline $2010-11$ & 12.88 & 9.46 \\
\hline $2011-12$ & 10.91 & 13.38 \\
\hline Average & 23.41 & 2.15 \\
\hline S.D. & 12.27 & 16.07 \\
\hline C.V. $(\%)$ & 52.41 & \\
\hline
\end{tabular}


Source:- Annual Reports and Accounts of the Companies under study

\section{Inference:}

It can be noted from the above table that the return on capital employed ratio of SAIL showed a decreasing trend throughout the period under study. During 2007-08 the ratio was 44.99 percent which continuously kept on decreasing and came down to 10.91 percent in 2011-12 which shows inefficiency of the management and signifies that the management of the company failed to make an optimum utilization of the capital funds. Such a situation cannot be regarded satisfactory. The average of the ratio was 23.41 percent which is though satisfactory but a decreasing trend of the ratio is a warning to the management. The fluctuations were also high as the coefficient of variation was 52.41 percent which should also be controlled.

For TISCO also the ratio of return on capital employed showed a decreasing trend during the whole period of study and varied within the range of 16.46 percent in 2007-08 to 9.98 percent in 2011-12. The average of the ratio was 13.38 percent which is though not poor but decreasing trend implies inefficient management. It is suggested that the management of the company should try to ratio by increasing the profit. The coefficient of variation was 16.67 percent denoting a moderate fluctuating trend but the decreasing trend should be controlled by the management.

On the whole it can be said that the return on capital employed position of SAIL was better than TISCO because the average of the ratio was higher but a decreasing trend in both the companies shows inefficiency of the management which should be controlled.

\section{Test of Significance ( $t$ - Test)}

Null Hypothesis : There is no significant difference in return on capital employed ratio of the companies under study.

Computed value of $t=1.80$

Critical value of $t$ at 5 percent level of significance $=2.31$

Decision: The null hypothesis is accepted because the computed value of $t$ is less than the critical value, hence it can be concluded that there is no significant difference in the return on capital employed ratio and both the companies are same as regards the return on capital employed ratio.

\section{Conclusion :}

(1)It is evident from the gross profit ratio of Tata Steel showed a decreasing trend and so is the case with SAIL, which shows inefficiency of the management, however on the basis of the average it can be concluded that Tata Steel performed better as the decrease is less than the decrease in the gross profit ratio of SAIL

Therefore it is suggested that management of both the companies should increase the gross profit ratio by controlling cost of goods sold and by increasing sales and try maintaining the same position in future also.

(2)The operating profit ratio was lower in SAIL and it is suggested that the company should try to increase this ratio and also high fluctuation should be controlled by management.

On the other hand the operating profit ratio was satisfactory in TISCO and it is suggested that company should try maintaining this ratio. Therefore it can be concluded that TISCO has performed better than SAIL from view point of this ratio as coefficient of variation was higher for SAIL than TISCO denoting variability.

(3)Analyzing the return on capital employed ratio it can be concluded that return on capital employed position of SAIL was better than TISCO because the average of the ratio was higher but the decreasing trend in both the company implies inefficiency of the management and inefficient utilization of the capital funds.

\section{References:}

[1]. Alicia Gazely \& Michael Lambert,(2006), "Management Accounting" North America, Sage Publications

[2]. Florence, P. Sargent \&Walker Glibort (2004), "Efficiency and Its Management" London: George Allen \& Unwin

[3]. Hingorani, N.L., Ramanthan A.R. and Grewal T.S.(2005), "Management Accounting" New Delhi, Prentice Hall of India.

[4]. Reports

[5]. Annual Reports and Accounts of Steel Authority of India Ltd. From 2007-08 to 2011-12.

[6]. Annual Reports and Accounts of Tata Iron \& Steel Co . Ltd from 2007-08 to 2011-12. 